\title{
Implementasi Pemrograman API dalam Membangun Aplikasi Rekening Bersama pada Komunitas Facebook dengan Virtual Account
}

\author{
${ }^{1}$ Dandy Raka Armadhana*, ${ }^{2}$ Eman Setiawan, ${ }^{3}$ Achmad Muchayan \\ ${ }^{1,2,3}$ Sistem Informasi, Fakultas Ilmu Komputer, Universitas Narotama
}

\author{
Alamat Surat \\ Email: dandyraka13@gmail.com
}

Article History:

Diajukan: 07 Agustus 2020; Direvisi: 23 Oktober 2020; Accepted: 23 Oktober 2020

\begin{abstract}
ABSTRAK
Aktivitas jual beli di dalam komunitas Facebook tidak semua dapat dipercaya, ada pula oknum yang melakukan penipuan yang dapat merugikan pihak yang terlibat transaksi. Rekber atau biasa disebut rekening bersama merupakan metode pembayaran online yang dianggap paling aman daripada melakukan transaksi secara mentransfer uang secara langsung. Oleh karena itu penelitian ini bertujuan untuk membangun aplikasi Rekberkuy pada komunitas facebook menggunakan pemrograman API. Pengambilan data pada penelitian ini didapatkan melalui wawancara dan observasi pada anggota grup XYZ di Facebook. Pada tahap pengembangan perangkat lunak, digunakan pendekatan prototyping dengan beberapa tahapan dan dibuat dalam jangka waktu 5 bulan. Hasil dalam penelitian ini yaitu implementasi payment gateway midtrans pada aplikasi rekberkuy berjalan dengan baik. Dengan melakukan testing pada transaksi beberapa customer menggunakan rekberkuy membuktikan bahwa system payment gateway midtrans berintegrasi dengan baik oleh rekberkuy dan mendapatkan komentar positif dari pembeli maupun penjual yang melakukan transaksi pada grup XYZ di Facebook.
\end{abstract}

Kata kunci: Integrasi API; Rekening Bersama; Gerbang Pembayaran

\section{ABSTRACT}

Not all buying and selling activities in the Facebook community can be trusted; some individuals make purchases involving parties involved in the transaction. Rekber, or commonly called a joint account, is an online payment method that is considered the safest way to directly make payment transactions. Therefore this research aims to build the Rekberkuy application in the Facebook community using API programming. Data collection in this study was obtained through interviews and observations on XYZ group members on Facebook. In software development, prototyping is used in several stages and made within five months. This study's results are the implementation of payment gateway mid trans on the rekberkuy application running well. By testing a transaction, several customers using Rekberkuy prove that the MidTrans gateway payment system integrates well with Rekberkuy and gets positive comments from buyers, both sellers who make transactions on the XYZ group on Facebook.

Keywords: API Integration; Escrow Service; Payment Gateway

\section{PENDAHULUAN}

Seiring berkembangnya internet yang pesat, media sosial tidak hanya digunakan sebagai alat komunikasi dan interaksi saja. Bermacam - macam penggunaan media sosial seperti untuk media promosi produk, karya, dan lain sebagainnya. Facebook, salah satu layanan jejaring sosial yang 
didirikan oleh Mark Zuckerberg pada tahun 2004 yang hingga saat ini memiliki banyak pengguna aktif di Indonesia maupun di seluruh dunia.

Facebook juga menyediakan fitur grup, yang bertujuan sebagai wadah komunitas dimana anggota dari komunitas tersebut dapat membahas suatu topik tertentu. Fitur ini dibuat karena grup Facebook telah berkembang sebagai wadah aktivitas jual beli yang meliliki 450 juta aktivitas jual beli tiap bulannya (Brügger, 2015).

Aktivitas jual beli di Facebook tidak hanya menjual barang saja, ada pula pengguna yang menawarkan jasa dan produk digital. Berbagai macam transaksi yang terjadi dalam grup Facebook tentunya tidak semua dapat dipercaya, ada pula oknum tak bertanggung jawab melakukan penipuan yang dapat merugikan pihak - pihak yang terlibat transaksi (Wahyuni, 2020).

Rekber atau biasa disebut sebagai rekening bersama merupakan metode pembayaran online yang dianggap sebagian orang paling aman daripada melakukan transaksi secara mentransfer uang secara langsung (Hakim, 2016). Metode ini biasanya lebih banyak dikenal pada kaum forum seperti kaskus, ada istilah khusus terkait rekber ini pada forum luar negeri rekber lebih dikenal sebagai escrow service (ES) (Atmojo et al., 2016). API (Application Programming Interface) terdiri dari berbagai elemen seperti function, protocols, dan tools lainnya yang memungkinkan developers untuk membuat aplikasi (Puspitasari \& Maulina, 2019).

Dalam upaya meminimalisir maraknya penipuan yang terjadi, umunya pengurus suatu komunitas online pada Facebook membuka jasa Rekening Bersama atau biasa disebut Rekber. Peran rekber disini sebagai pihak ketiga dari transaksi yang dilakukan oleh penjual dan pembeli. Hal ini dimaksudkan untuk saling membangun kepercayaan dan menjaga keamanan transaksi yang menguntungkan semua pihak, Tetapi rekber melalui pengurus menggunakan cara manual, seperti menghubungi semua pengurus yang sedang aktif (online) terlebih dahulu (Atmojo et al., 2016). Pada penelitian yang pernah dilakukan, implementasi payment gateway dari midtrans dapat dilakukan pada pemesanan tiket tour, dengan hasil yang sangat memuaskan baik dari pengguna maupun dari pemilik tour (Rahardika, 2020). Pada penelitian yang pernah dilakukan terkait implementasi payment gateway pada midtrans yang diaplikasikan pada e-commerce Dazzle dapat membantu pihak toko merasakan efektifitas dari adanya payment gateway karena tidak adanya pengecekan secara manual dikarenakan midtrans memiliki pengecekan sistem secara otomatis (Febrianto, 2020). Pada penelitian berikutnya yang memanfaatkan integrasi payment gateway dari midtrans adalah penerapan pada sistem informasi e-commerce dengan mengggunakan rest-full API yang mana hasil akhirnya dapat dikatakan sukses berhasil (Setiawan, 2018).

Maka dari itu penulis ingin membuat sistem rekber yang dapat diakses kapanpun secara online. Rekberkuy merupakan sistem keamanan transaksi online berbasis web dengan metode pembayaran virtual account. Dengan Rekberkuy, pihak pembeli mendapat jaminan transaksi karena uang tidak langsung masuk ke rekening penjual. Sedangkan bagi pihak penjual tidak perlu khawatir jika barang atau jasa tidak dibayakan, karena uang pembelian sudah ada di pihak Rekberkuy dan siap diberikan ke pihak penjual jika pembeli merasa transaksi sudah selesai.

\section{METODE}

Dalam penelitian ini, penulis akan menggunakan beberapa metode yang bertujuan guna mempermudah ketika melakukan sebuah Analisa, penulisan serta pengembangan perangkat lunak dengan menggunakan pendekatan prototyping (Jiang \& Lu, 2012).

\subsection{Metode Pengembangan Perangkat Lunak}

Dalam pengembangan perangkat lunak yang penulis gunakan kali ini adalah pengembangan perangkat lunak prototyping, tahapan prototyping dapat dilihat pada Gambar 1. 


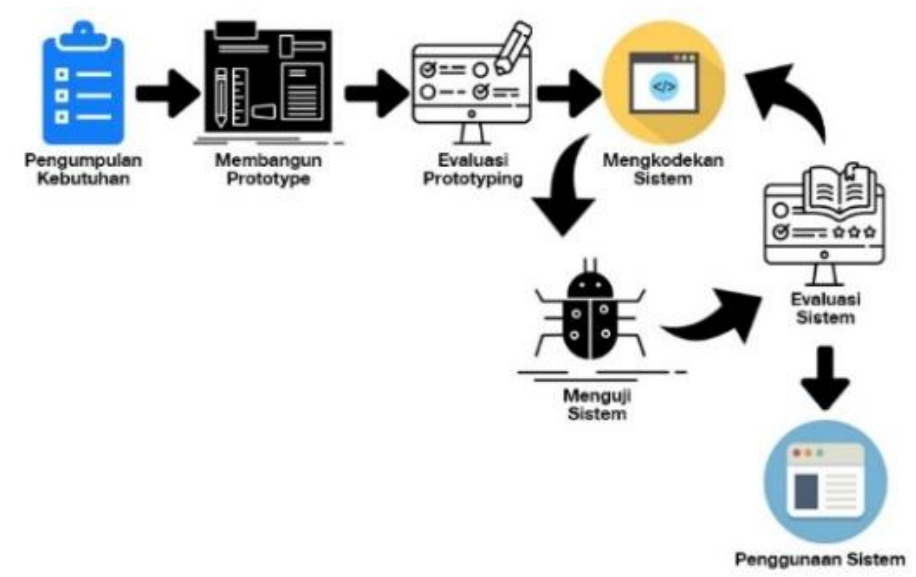

Gambar 1. Pendekatan Prototyping

\subsection{Arsitektur Diagram Secara Umum}

Pada arsitektur sistem ini menjelaskan sistem yang akan dibangun. Berikut adalah gambar dari arsitektur sistem ini secara umum dapat dilihat pada Gambar 2 (Muttaqin \& Ajib Susanto, 2020).

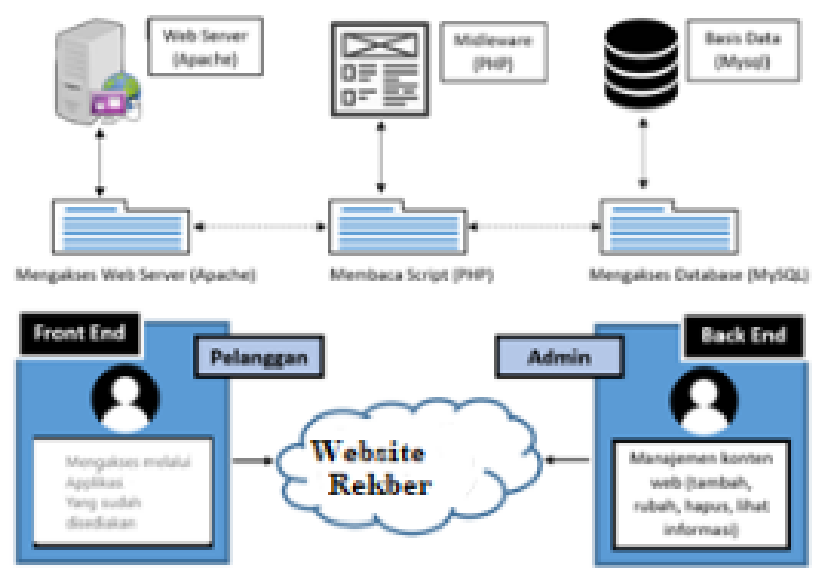

Gambar 2. Arsitektur Diagram

\subsection{Perancangan Sistem}

\subsubsection{Perancangan Usecase Diagram}

Perancangan Usecase Diagram digunakan sebagai mengetahui fungsi apa saja yang terdapat dalam perangkat lunak rekberkuy, dapat dilihat pada Gambar 3 dan Gambar 4 (Zaman, Nadeem, \& Sindhu, 2020).

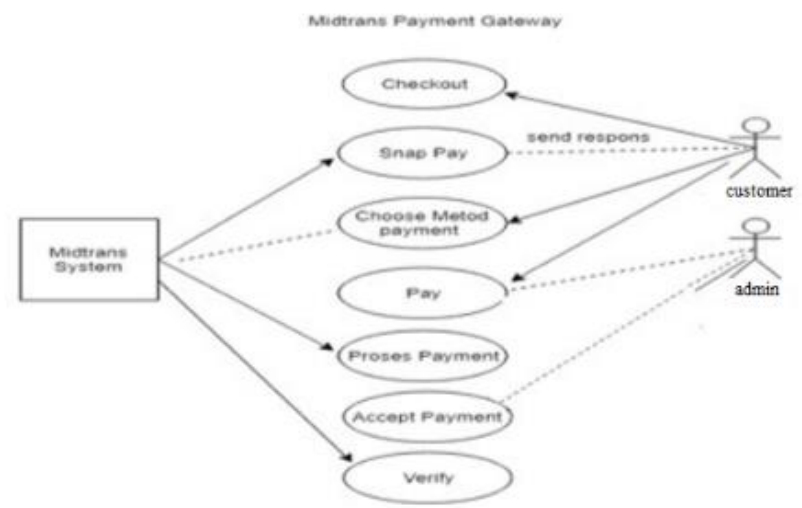

Gambar 2. Usecase Diagram Midtrans Gateway 


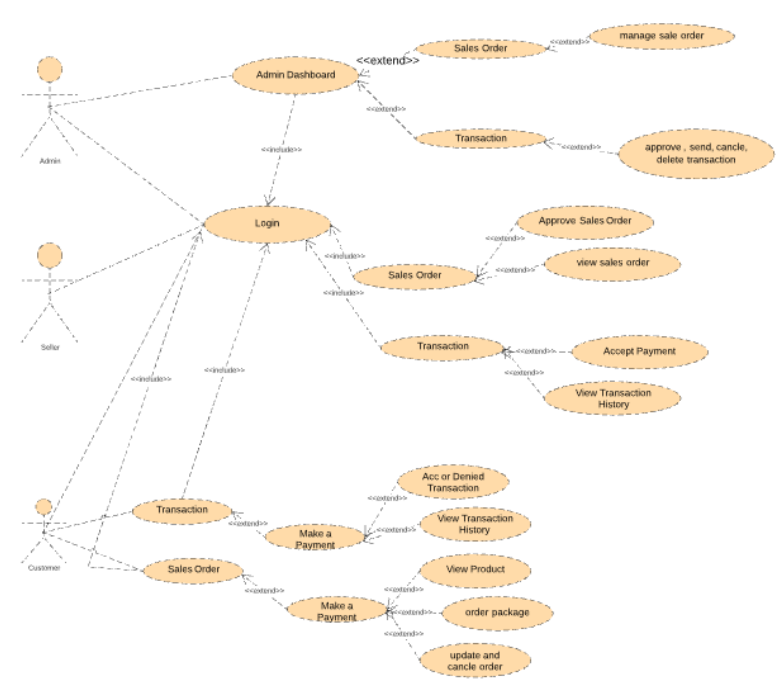

Gambar 3. Usecase Diagram Rekberkuy

\subsubsection{Perancangan Activity Diagram}

Perancangan Activity Diagram digunakan sebagai penggambaran dari proses bisnis perangkat lunak rekberkuy, dapat dilihat pada Gambar 5 (Rodríguez, Fernández-Medina, Trujillo, \& Piattini, 2011).

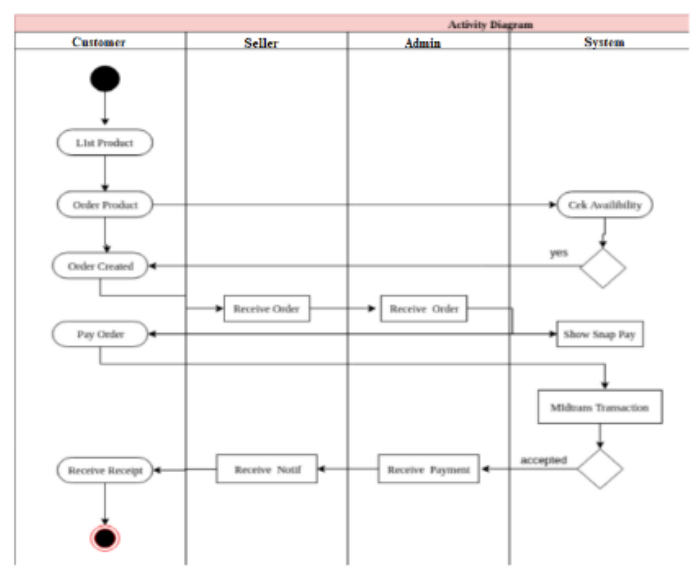

Gambar 4. Activity Diagram

\subsubsection{Perancangan Sequence Diagram}

Perancangan Sequence Diagram pada pengembangan perangkat lunak rekber-kuy digunakan sebagai menggambarkan scenario dari suatu even yang terjadi , dapat dilihat pada Gambar 6 (Alshayeb, Mumtaz, Mahmood, \& Niazi, 2020).

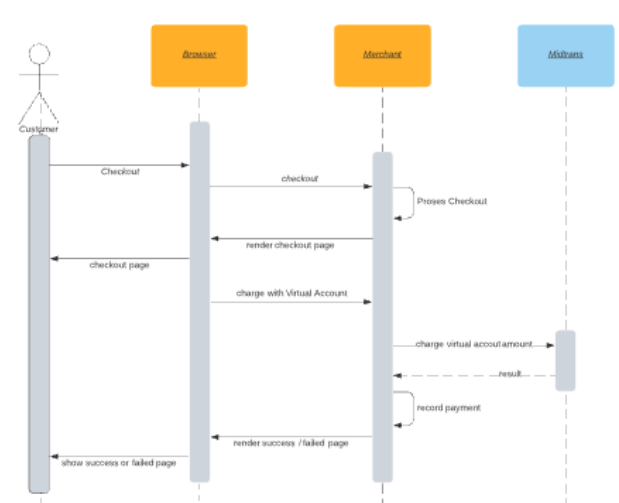

Gambar 5. Sequence Diagram 


\subsubsection{Perancangan Diagram Hubungan Entitas}

Perancangan Diagram Hubungan Antar entitas dalam pengembangan perangkat lunak rekberkuy digunakan sebagai penggambaran antar entitas yang ada sehingga memudahkan ketika proses pembuatan coding perangkat lunak rekberkuy. Dapat dilihat pada Gambar 7 (Felderer \& Herrmann, 2019).

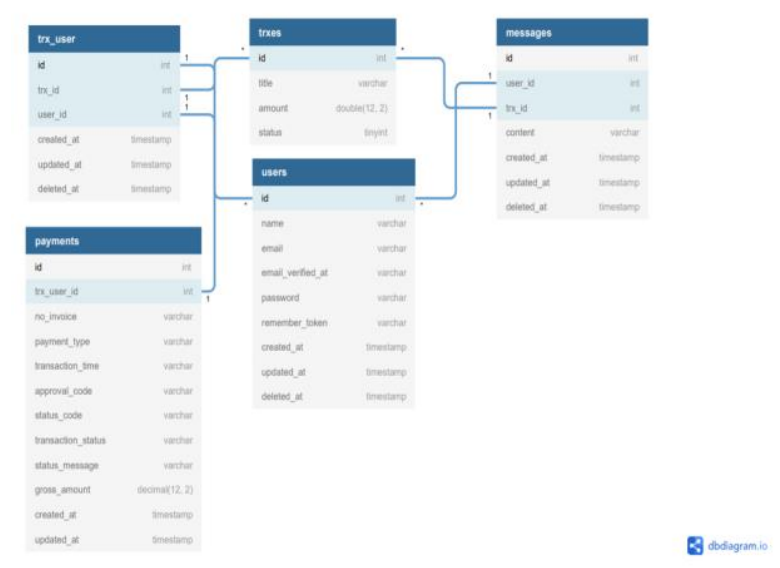

Gambar 6. Diagram Hubungan Entitas

\section{HASIL DAN PEMBAHASAN}

\subsection{Hasil}

Hasil dari penelitian penulis adalah mengimplementasikan payment gateway midtrans ke dalam rekberkuy, hasil dari pengembangan perangkat lunak rekberkuy menghasilkan juga tampilan backend dan front-end. Gambar 8 merupakan tampilan dari customer ketika melakukan checkout produk.

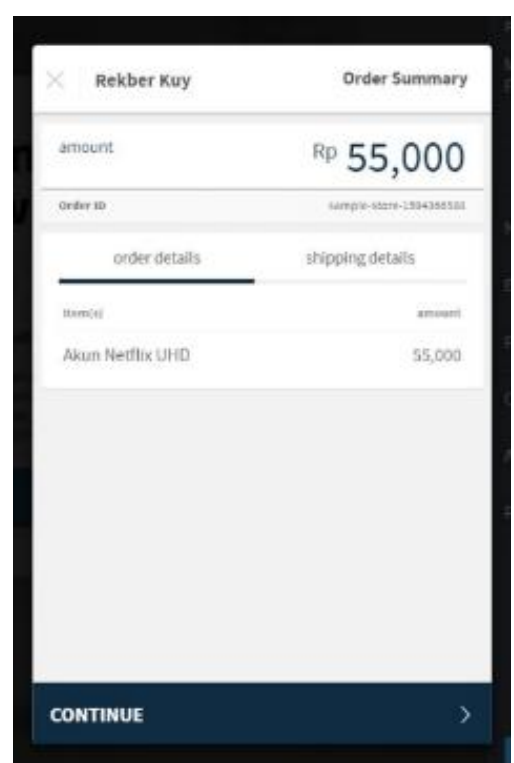

Gambar 8. Tampilan Customer Checkout

Pada tampilan checkout diatas, merupakan tampilan dimana customer akan disuguhkan halaman checkout berisikan nama produk atau jasa yang telah dipesan, jumlah yang harus dibayar dan button continue guna melanjutkan tahap pembayaran. Setelah customer melakukan aktivitas klik pada button continue, maka customer akan disuguhkan oleh halaman pemilihan pembayaran, pada halaman pembayaran inilah customer dapat memilih beberapa pilihan seperti pembayaran melalui ATM, melalui debit atau kartu kredit, pembayaran melalui virtual account, pembayaran melalui indomaret dan lain sebagainya. Dapat dilihat pada Gambar 9 : 


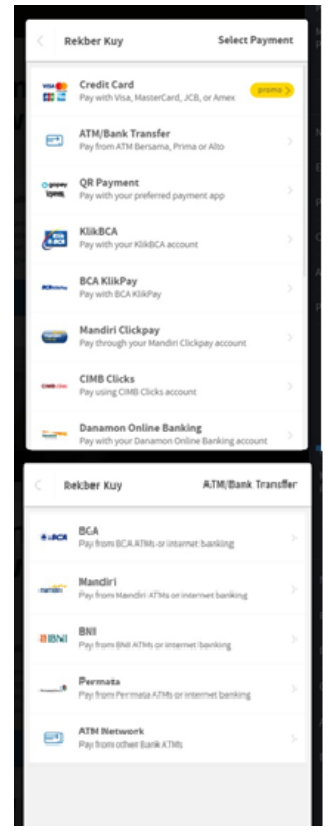

Gambar 9. Tampilan Pilih Pembayaran

Kemudian Gambar 10 sampai Gambar 15 bahwasanya menampilkan gambar design interface mengenai tampilan loading page, live chat, detail transaksi, pilih pembayaran, detail pembayaran virtual account, dan payment complete yang akan disajikan kepada costumer saat mengakses rekberkuy, diantaranya:

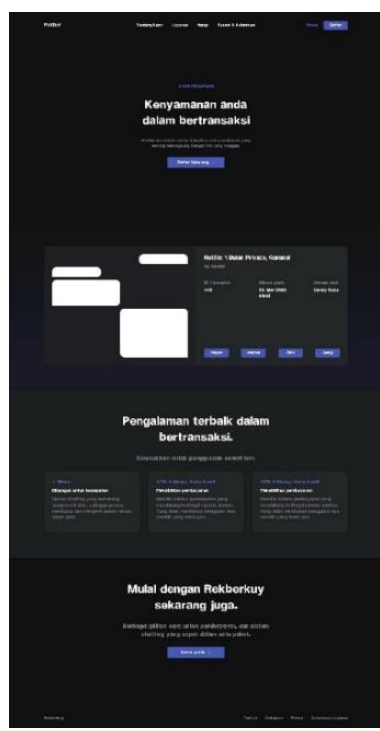

Gambar 10. Tampilan Landing Page

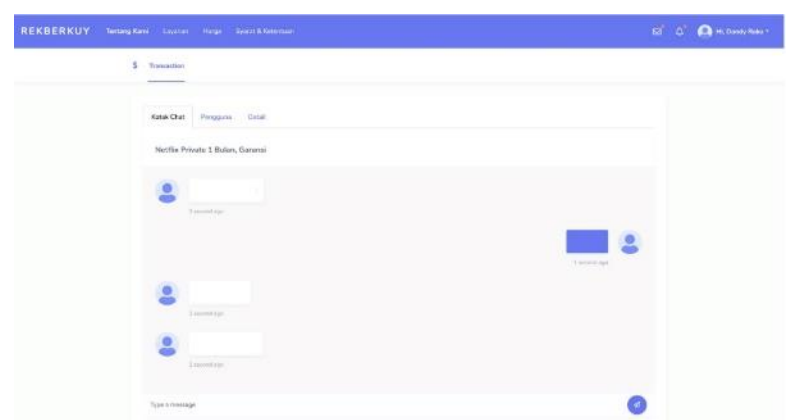

Gambar 11. Halaman Live Chat 


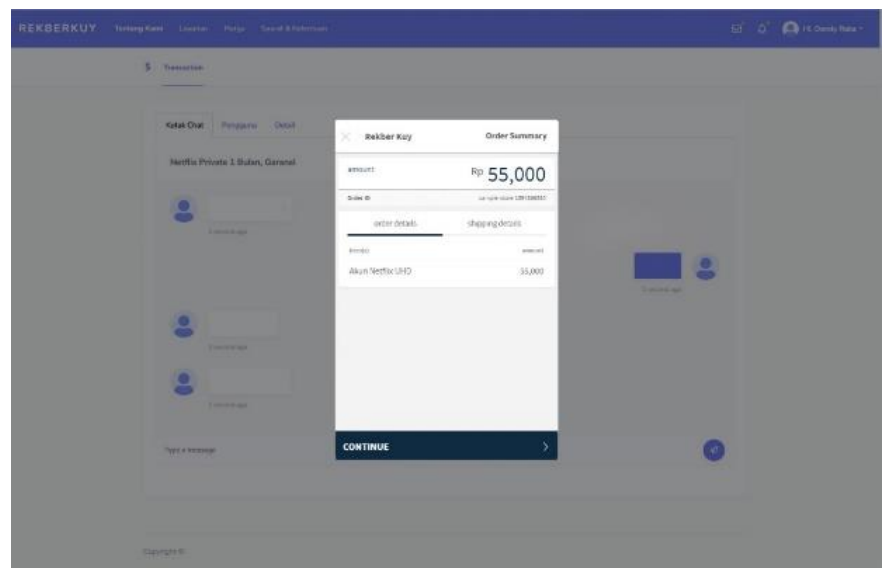

Gambar 12. Tampilan Detail Transaksi

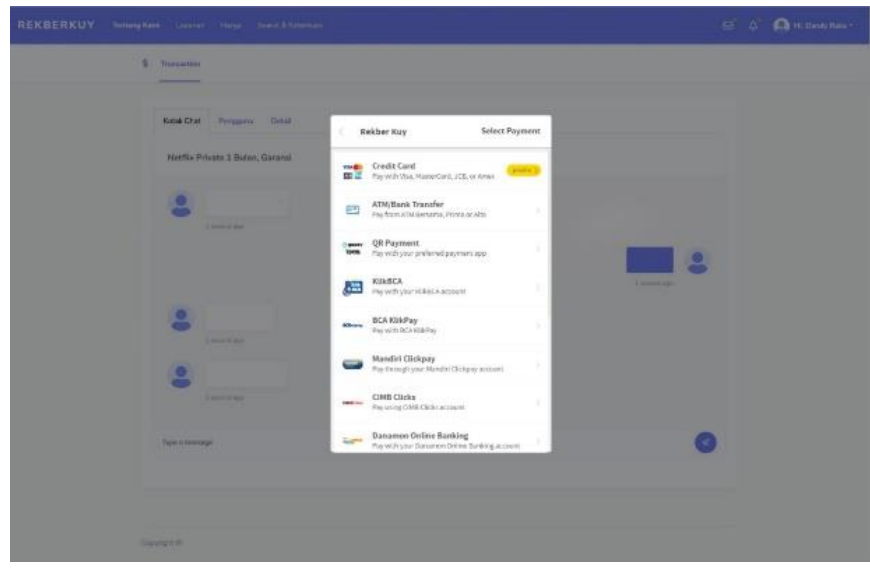

Gambar 13. Tampilan Pilih Pembayaran

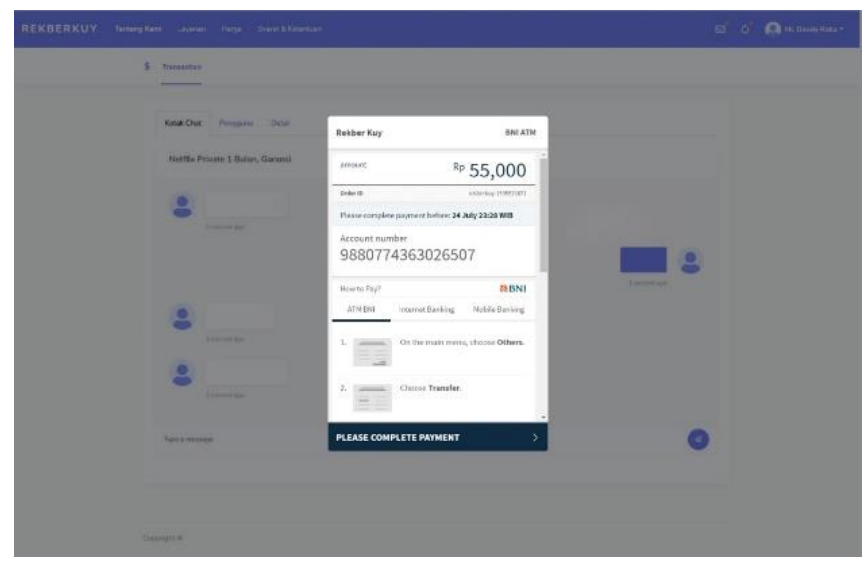

Gambar 14. Tampilan Detail Pembayaran Virtual Account

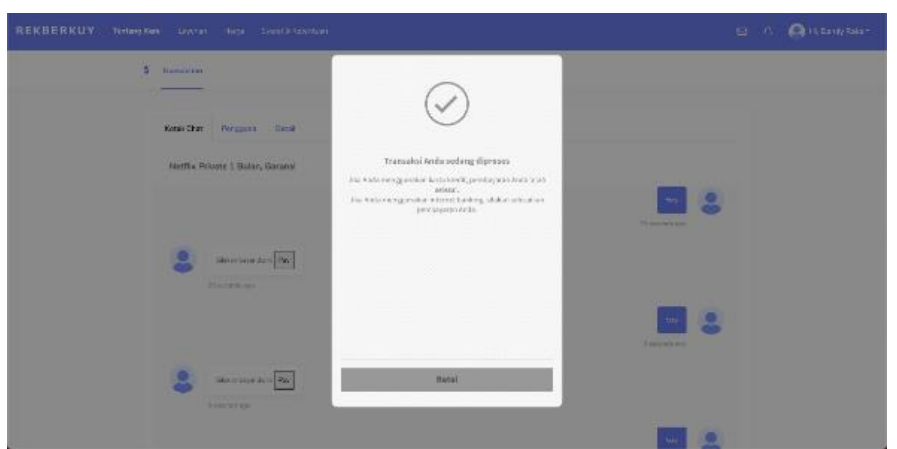

Gambar 15. Tampilan Payment Complete 


\subsection{Pembahasan}

Hasil kegiatan disampaikan terlebih dahulu secara keseluruhan, yang dilanjutkan dengan melakukan proses pembahasan. Pembahasan disajikan secara sistematis dari umum, kemudian mengarah pada yang spesifik. Presentasi hasil dapat dilakukan dengan bantuan tabel, gambar / grafik, peta / rencana, dan skema. Selain itu, hasil dan pembahasan yang disajikan juga saling berhubungan dengan teori yang digunakan:

- Customer akan melakukan checkout pada pemesanan Netflix di Rekberkuy, kemudian customer akan mendapatkan sebuah id_order

- Tahap berikutnya, pada server backend akan membuat request API pada snap, untuk mendapatkan SNAP_TOKEN, SNAP_TOKEN akan didapatkan ketika proses order telah masuk kedalam record payment, setelah record tersebut tersimpan maka akan memunculkan snap pay

- Snap Backend akan merespon request API dengan SNAP_TOKEN yang sudah didapatkan

- Server dari Rekberkuy akan membuat sebuah halaman yang berisikan kode pembayaran dan detail order

- Customer akan memverifikasi detail dan melakukan aktivitas klik pada tombol bayar. Kode dari javascript dari seller akan memanggil snap payment.

- Snap.js akan mengirimkan sebuah detail pembayaran pada backend snap

- Snap backend akan merespon detail dengan merespon status pembayaran yang sudah dilakukan

- Snap backend akan memberitahukan status pada server merchant terkait status pembayaran yang telah dilakukan pada customer.

Implementasi config code yang digunakan agar payment gateway midtrans mampu terintegrasi dengan baik oleh rekberkuy dengan menggunakan config.js yang berisikan client dan server key guna menjadi pintu masuk saat dilakukannya request payment, save record payment pada midtrans, dapat dilihat pada Gambar 16:

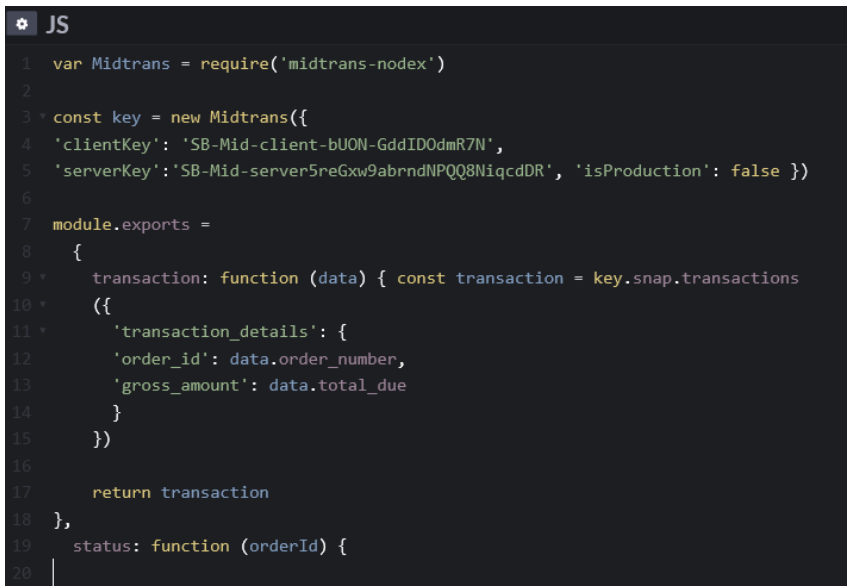

Gambar 16. Code Listing Config.js

\section{KESIMPULAN}

Dari hasil pembahasan penelitian yang dilakukan oleh penulis, maka dapat ditarik sebuah kesimpulan diantaranya yaitu :

- Payment Gateway midtrans dapat berjalan dengan baik sesuai yang diharapkan oleh penulis

- Dari sudut pandang customer, dengan adanya payment gateway menjadi lebih efektif karena customer tidak perlu konfirmasi secara manual apabila customer telah melakukan pembayaran karena payment gateway midtrans akan mengirimkan pemberitahuan secara otomatis apakah sudah ada dana yang masuk atau tidak, dan transaksi yang berhasil atau tidak 


\section{DAFTAR PUSTAKA}

Alshayeb, M., Mumtaz, H., Mahmood, S., \& Niazi, M. (2020). Improving the Security of UML Sequence Diagram Using Genetic Algorithm. IEEE Access. https://doi.org/10.1109/ACCESS.2020.2981742

Atmojo, R. N. P., Tjhin, V. U., Wandoko, W., Budiastuti, D., Polla, G., Mahesa, R., \& Astuti, T. N. K. (2016). Rekening Bersama (RekBer) the Indonesian escrow service of money. International Journal of Multimedia and Ubiquitous Engineering. https://doi.org/10.14257/ijmue.2016.11.3.38

Brügger, N. (2015). A brief history of facebook as a media text: The development of an empty structure. First Monday. https://doi.org/10.5210/fm.v20i5.5423

Febrianto, M. (2020). Penerapan Payment Gateway Dan Tracking Barang Pada E-Commerce Toko Dazzle Berbasis Website. University of Technology Yogyakarta.

Felderer, M., \& Herrmann, A. (2019). Comprehensibility of system models during test design: a controlled experiment comparing UML activity diagrams and state machines. Software Quality Journal, 27(1), 125-147.

Hakim, F. N. (2016). Modal Simbolik Dalam Strategi Membangun Kepercayaan Pelaku Onlineshop. NATAPRAJA. https://doi.org/10.21831/jnp.v4i1.12616

Jiang, F., \& Lu, Y. (2012). Software testing model selection research based on Yin-Yang testing theory. 2012 International Conference on Computer Science and Information Processing (CSIP), 590-594. IEEE.

Muttaqin, M. A., \& Ajib Susanto, M. (2020). Aplikasi Stok Audit di PT. Media Sarana Data Berbasis Android Dengan Arsitektur Model View Presenter. Jurnal Maklumatika, 6(2).

Puspitasari, T. M. M., \& Maulina, D. (2019). Implementasi Payment Gateway Menggunakan Midtrans Pada Marketplace Travnesia.Com. Mobile and Forensics. https://doi.org/10.12928/mf.v1i1.997

Rahardika, P. (2020). Implementasi Sistem Pembayaran Dengan Payment Gateway Pada Pemesanan Tour \& Transport (Studi kasus PT. Hanoman Pandu Wisata). University of Technology Yogyakarta.

Rodríguez, A., Fernández-Medina, E., Trujillo, J., \& Piattini, M. (2011). Secure business process model specification through a UML 2.0 activity diagram profile. Decision Support Systems. https://doi.org/10.1016/j.dss.2011.01.018

Setiawan, A. J. (2018). Implementasi Representational State Transfer (REST) pada Checkout \& Payment Gateway Service dalam Sistem Informasi E-Commerce menggunakan Teknologi Web Service. Universitas Pendidikan Indonesia.

Wahyuni, S. A. (2020). Praktik Jual Beli Handphone Bekas Di Sosial Media Facebook Perspektif Undang-Undang Nomor 8 Tahun 1999 Tentang Perlindungan Konsumen Dan Fiqh .... Journal of Islamic Business Law.

Zaman, Q. uz, Nadeem, A., \& Sindhu, M. A. (2020). Formalizing the use case model: A model-based approach. Plos One, 15(4), e0231534. 